\title{
The Salford Asthma Register
}

\section{A mechanism for auditing a district asthma population and supporting asthma care}

\section{A Raghuram, SJ Ansted, D McDowell, RH Davenport and BR O'Driscoll on behalf of Salford and Trafford Asthma and Respiratory Team (START)}

\section{Ananthakrishnan \\ Raghuram \\ Specialist Medical \\ Registrar}

\section{Sarah Ansted}

Project Manager, Clinical

Informatics Department

David McDowell

Principal Biochemist

\section{Robert Davenport}

General Practitioner

\section{Ronan O'Driscoll \\ Consultant Respiratory Physician}

On behalf of Salford and Trafford Asthma and Respiratory Team, Department of Cardiorespiratory Medicine, Salford Royal Hospitals NHS Trust, Hope Hospital, Salford M6 8HD, UK

Correspondence to: Dr A Raghuram Chest Clinic, Stepping Hill Hospital, Poplar Grove, Stockport SK2 7JE, UK Ananthakrishnan. Raghuram@stockport-tr. nwest.nhs.uk

Date received: $10 / 05 / 00$ Date accepted: 12/07/00

\begin{abstract}
Objectives: The Salford Asthma Register was launched at the beginning of 1995 to record the details of all asthma patients in Salford, Greater Manchester, UK.

Design: An IT system was developed for the registration, annual review, audit and feedback of data to general practices on the status of their registered asthma patients.

Setting and subjects: On joining the Salford Asthma Register, each practice submits a list of their current asthma patients to a central database maintained at Hope Hospital. Patients with chronic obstructive pulmonary disease (COPD) and children below one year of age are excluded from the register.

Main outcome measures: An annual review sheet for every registered patient is generated by the database and returned to the practice. Asthma patients numbering 10,841 have been registered from 41 general practices covering $70 \%$ of the population of Salford. Of these, 2244 (20.7\%) have had an annual review and $1545(14.3 \%)$ have been recorded as resolved. All participating practices have received annual asthma reports comparing their asthma management with the district average. Most asthma measures (peak expiratory flow, daytime and nighttime symptoms) progressively deteriorated from the BTS Step 1 to Step 5. We were able to identify possible under-treatment in some patients in Step 1 and provide feedback to the practices concerned. Conclusions: In this observational study, we have shown that it is possible to establish a broad-based asthma database in an NHS district, which provides valuable feedback to the primary care team. We feel that this database and asthma monitoring methodology could be utilised elsewhere in the country. This could be an important tool in clinical governance.
\end{abstract}

\section{INTRODUCTION}

In 1990, the British Thoracic Society (BTS) produced guidelines ${ }^{1}$ for the management of asthma. Revised in 1993 and 1997, this involved a step-wise management plan for the care of patients with asthma. ${ }^{2,3}$ The National Health Service (NHS) encourages local programmes for the management of chronic diseases, and the Royal College of Physicians has produced recommendations about measuring clinical outcome in asthma using a patient-focused approach. ${ }^{4}$ It was felt that the next step should be to test this measure in clinical practice and investigate how this could be incorporated into the NHS information system. In Salford, there is an existing database of all known diabetic patients. ${ }^{5}$ This asthma database was developed on similar lines.

The Salford Asthma Register, which was launched at the beginning of 1995, aims to record details of all asthma patients in Salford in Greater Manchester (population 220,000) in one central database. An IT system was developed for the registration, annual review, audit and feedback of data to general practices on the status of their registered asthma patients.

The dataset used was developed by the Salford Asthma Group, which later amalgamated with colleagues in Trafford to form the Salford and Trafford Asthma and Respiratory Team (START). This is a multidisciplinary team dedicated to improving the care given to patients with respiratory conditions and includes consultant physicians and paediatricians, general practitioners (GP), pharmacists and respiratory nurse specialists. The database has not yet been implemented in Trafford due to the absence of a data co-ordinator.

\section{AIM}

The aim of launching the Salford Asthma Register was to record the details of all asthma patients in Salford by establishing a broad-based asthma database in an NHS district.

By encouraging every general practice in Salford to follow the BTS asthma guidelines and to collect the same minimum dataset for each of their patients, we hoped to standardise the quality of care given to asthma patients. We expected that the project would identify the areas of strength and those needing improvement. The register was designed to provide practices with time and support to complete the audit cycle and to provide feedback about individual patients with pre-defined markers of poor asthma control.

\section{METHOD}

All asthma patients are registered on a central database designed by Westman Medical Software (Manchester). The Westman systems also support projects in diabetes, coronary heart disease and haematology. On joining the Salford Asthma Register, each practice submits a list of their current asthma patients. Patients with chronic obstructive pulmonary disease (COPD) and children less than one year of age are excluded from the register. Patients who have had no asthma symptoms or treatment for a year are recorded as resolved. An annual review sheet for every registered patient is then generated by the database and returned to the practice. All GPs and practice nurses in Salford were provided with personal copies of the BTS asthma guidelines in 1993 and 1997 and educational meetings are held regularly to enhance local implementation. We obtained informed consent from the patients before entering their details on the database and confidentiality was maintained. Patients were identified by their unique hospital number or their NHS number.

Once a year, the GP or, more commonly, the practice nurse completes the review sheet for each asthma patient that attended a clinic. The review sheet is then returned to the audit facilitator for input into the asthma register. In the second, and subsequent, annual 
Table 1: Relationship between BTS treatment step and asthma status

\begin{tabular}{lrcccc} 
BTS step $\mathrm{n}=\mathbf{2 2 4 4}$ & $\mathbf{1}$ & $\mathbf{2}$ & $\mathbf{3}$ & $\mathbf{4}$ & $\mathbf{5}$ \\
\hline $\begin{array}{l}\text { \% of patients } \\
\text { \% with PEF }\end{array}$ & 18.4 & 55.4 & 21.3 & 4.2 & 0.7 \\
$\begin{array}{l}\text { 80\% predicted } \\
\text { \% waking nightly }\end{array}$ & 62.9 & 75.1 & 62.8 & 40 & 25 \\
$\begin{array}{l}\text { \% GP call out } \\
\text { \% hospital-treated }\end{array}$ & 12.5 & 25.5 & 39.6 & 55.4 & 41.7 \\
exacerbation & 1.5 & 3.3 & 8.0 & 14.9 & 38.5
\end{tabular}

Table 2: Daytime symptoms according to BTS treatment steps

\begin{tabular}{lccccc} 
BTS step & $\mathbf{1}$ & $\mathbf{2}$ & $\mathbf{3}$ & $\mathbf{4}$ & $\mathbf{5}$ \\
\hline No symptoms & $59.1 \%$ & $45.7 \%$ & $24.9 \%$ & $13.0 \%$ & $21.4 \%$ \\
$\begin{array}{l}\text { Breathless running } \\
\text { Breathless }\end{array}$ & $29.9 \%$ & $32.3 \%$ & $31.1 \%$ & $18.2 \%$ & $14.3 \%$ \\
climbing stairs & $7.0 \%$ & $13.5 \%$ & $24.0 \%$ & $24.7 \%$ & $28.6 \%$ \\
$\begin{array}{l}\text { Breathless walking } \\
\text { Breathless at rest }\end{array}$ & $3.8 \%$ & $8.0 \%$ & $18.5 \%$ & $41.6 \%$ & $35.7 \%$ \\
& $0.3 \%$ & $0.4 \%$ & $1.5 \%$ & $2.6 \%$ & 0
\end{tabular}

review sheets, the patient's previous data are printed above the blank spaces for the current year's data. This allows a GP or nurse to keep a longitudinal record for each individual patient.

\section{RESULTS}

There are 10,841 asthma patients who have been registered from 41 general practices covering $70 \%$ of the population of Salford. Of these, 2244 (20.7\%) have had an annual review and 1545 (14.3\%) have been recorded as resolved. A large number of patients with COPD rather than asthma have been removed from the practice asthma registers. These patients constituted about $10-20 \%$ of the cases on previous paper-based asthma registers. All the 41 practices have now received reports, providing individual practices with a printout of their data compared to the district average. General practitioners have also been provided with a list of names of patients who may need further intervention, such as patients at BTS steps 1 or 2 with nightly symptoms or GP call-outs. The average asthma prevalence per registered practice is $6.9 \%$ (range 2 to 15 ). The extremes of ranges probably reflect over or under-diagnosis of asthma.

The number of patients at each BTS step along with the details of the peak expiratory flow (PEF), nocturnal symptoms, the incidence of GP callout and Accident and Emergency (A\&E) attendance in the previous year are recorded in Table 1. Daytime symptoms according to the BTS treatment steps are shown in Table 2. The smoking status of 653 Salford asthma patients is recorded in Table 3. The BTS treatment step of patients in various age bands is shown in Table 4. Of those reviewed, $48.7 \%$ had a self-management plan and the reporting nurse or doctor was satisfied with the patient's inhaler technique in $87 \%$ of the cases.

\section{DISCUSSION}

This is an observational study describing how an asthma database can help GPs care for their asthma patients. The data provided in the register are accurate and up to date and will help in the production of annual reports for chronic disease management.

We have shown that it is possible to establish a broadbased asthma database in a NHS district, although a significant minority of practices has not yet joined the project and some practices have submitted few annual review documents. We plan to increase the level of support to GPs and practice nurses to collect the data which have been of great value to the participating practices. Computerised practices have had particular difficulty with a paper-based audit system and we hope that future systems will be computer-based and

linked directly to the primary care computer.

The data in the register provided a unique opportunity to validate the BTS treatment steps as most asthma measures progressively deteriorated from Step 1 to

Step 5. We are unaware of any previously published data from unselected primary care patients which have illustrated so clearly that GPs seem to provide appropriate therapy for the great majority of their asthmatic patients. The database allows each GP to compare the prevalence, severity, management and outcomes of asthma in his/her practice with other practices in the district. This also helps to identify patients whose symptoms are inappropriate to their BTS steps. We found that $8.6 \%$ of patients at BTS step 1 had regular nocturnal symptoms and one-third had PEF lower than expected. Furthermore, the PEF fell progressively from BTS step 2 to step 5 as one might predict. However, patients at BTS step 1 had a lower PEF (as \% predicted) than patients in step 2 and they were almost as low as patients in step 3 . This confirms the benefit of adding inhaled steroid therapy (step 2) and indicated that about one third of patients at step 1 may be under-treated. We documented a high prevalence of nocturnal asthma symptoms; $13 \%$ of asthma patients had symptoms every night, 53\% of these were at BTS steps 1 and 2. It is likely that many patients in step 1 are under-treated due to reluctance of patients or their doctors to use regular prophylactic therapy or due to failure by the healthcare professionals to recognise the severity of asthma in some cases.

The asthma database allows GPs and practice nurses to focus resources on patients with the most severe asthma. Analysis of the age breakdown of the data shows that more patients are on higher treatment steps with increasing age, suggesting a trend for asthma to deteriorate with age. Of adults reviewed, $46.1 \%$ were current or ex-smokers. This figure is similar to the smoking status of the general population of Salford as assessed by a recent survey of 1200 Salford residents conducted by the START team. ${ }^{6}$
Table 3: Smoking habits in age bands

\begin{tabular}{lcccc} 
Age group & Total & $\begin{array}{c}\text { Never Ex-smoker } \\
\text { smoked } \\
\%\end{array}$ & n & $\begin{array}{c}\text { Current } \\
\text { smoker } \\
\%\end{array}$ \\
\hline $\mathbf{1 7 - 4 0}$ & 271 & 59.8 & 12.1 & 28 \\
$\mathbf{4 1 - 6 0}$ & 186 & 53.2 & 28 & 18.8 \\
$>60$ & 196 & 46.4 & 45.4 & 8.7 \\
Total & 653 & 53.9 & 26.5 & 19.6
\end{tabular}

Table 4: BTS treatment steps in age bands

\begin{tabular}{lccccl} 
Age band & $\mathbf{1}$ & $\mathbf{2}$ & $\mathbf{3}$ & $\mathbf{4}$ & $\mathbf{5}$ \\
\hline$<\mathbf{1 7}$ & $26.9 \%$ & $59.1 \%$ & $12.8 \%$ & $1.2 \%$ & - \\
$\mathbf{1 7 - 5 0}$ & $19.2 \%$ & $57.5 \%$ & $19.0 \%$ & $3.7 \%$ & $0.6 \%$ \\
$>\mathbf{5 0}$ & $7.1 \%$ & $48.5 \%$ & $34.3 \%$ & $8.3 \%$ & $1.7 \%$
\end{tabular}


The Tayside asthma management initiative was set up with an aim to provide a primary care led regional asthma management service in Tayside (Dundee, UK). Thirty-two $(41 \%)$ of their practices participated in an asthma management initiative comprising a clinical review of 30 patients leading to patient-specific feedback based on the management. ${ }^{7}$ Using a standardised package linking clinical care with nurse activity and audit, a regional database of clinical outcome was created. By utilising the Salford Asthma Register, we are able to provide feedback on all patients on our database.

In a paper describing asthma management in general practice in 1997 , Waring ${ }^{8}$ reported that $40.6 \%$ of his patients were in step $1,29.7 \%$ in step $2,8.0 \%$ in step 3 , and 5\% in step 4 and none in step 5. This contrasts with our data where more than half of our population was in step 2. It was suggested that a further step zero be considered if the patients did not receive any treatment for two years. We maintain these patients on our database, but not as active asthma cases. This may explain why the Salford database has fewer patients at step one. They are reinstated in the active database if their disease recurs.

In 1993, Whiteman and Gaduzo ${ }^{9}$ published a retrospective analysis of management of patients with mild to moderate asthma. About a quarter of their patients were prescribed five or more $\beta$-agonists without use of appropriate anti-inflammatory agents. Almost half of their patients had received repeat prescription for their asthma without consulting the general practitioner. Our database identifies patients with an inappropriate level of symptoms (for their present BTS step). The data co-ordinator alerts the GP of such patients who require more intense asthma therapy.

In his editorial in Respiratory Medicine, Partridge ${ }^{10}$ suggested that simple practice-based education, combined with patient-specific reminders and audit would be likely to improve both the process and outcome of care. We feel that this database will help towards the achievement of this goal.

There was initial reservation from some practice nurses; however, it was found that, on searching practice computer records, a large number of patients on asthma registers had COPD or inactive asthma. Therefore the workload was not as great as had been expected by some of the nurses. It is now felt that the database provides an efficient way to review asthma patients. It is also possible to highlight patients who do not attend their reviews. It also became recognised by the then Family Health Services Authority as meriting payment for health promotion activities. The data are absolutely confidential, as there is no outside agency involved. The Data Manager is a hospital employee fully bound by NHS confidentiality contracts. We do not have trend data yet as we have had some problems with data collection. Future projects should look at the role of practice nurses, health visitors, nurse practitioners, district nurses and respiratory nurses in finding means of contacting the reluctant attendees.

The primary care groups in whatever form they take will make use of this register as the most efficient means of caring for the asthma patients making it an effective tool for clinical governance.

\section{Acknowledgements}

A great deal of thanks is due to the many different contributors to this database and the START group.

\section{Conflict of interest}

Dr David McDowall who is a principal biochemist at Hope Hospital is the director of Westman Medical Software (Manchester).

\section{References}

1. British Thoracic Society, Research Unit of the Royal College of Physicians of London, King's Fund Centre, et al. Guidelines for the management of asthma in adults. 1Chronic persistent asthma. BMJ 1990;301:651-3

2. British Thoracic Society, British Paediatric Association, Royal College of Physicians of London, et al. Guidelines on the management of asthma. Thorax 1993;48:S1-24

3. The British Thoracic Society, the National Asthma Campaign, the Royal College of Physicians of London, et al. The British guidelines on asthma management: 1995 Review and position statement. Thorax 1997;52:S1-21

4. Royal College of Physicians. Clinical effectiveness and evaluation unit. Pearson MG and Bucknall CE (eds). In: Measuring clinical outcome in asthma - A patient focused approach. London: Royal College of Physicians; 1999

5. New JP, Campbell F, Hollis S, et al. A robust method for analysing changes in health care provision. Diabetes 1998;47:A1

6. Raghuram A, Houghton CM, Ansted SJ, et al. Smoking habits of asthma patients in Salford (Northwest England). Eur Respir J 1999;14 (Suppl) 30:139s

7. Hoskins G, Smith B, Neville RG, et al. The Tayside asthma management initiative. Health Bulletin 1998;56(2):586-91

8. Waring N. Use of new asthma BTS steps in one general practice - Should asthmatics no longer on treatment be followed-up? Asthma Gen Pract 1997;5(2):28

9. Whiteman IA, Gaduzo SC. The management of mild to moderate asthmatics in general practice: A retrospective analysis. Br J Med Econ 1993;6:25-35

10. Partridge MR. The implementation of asthma guidelines in general practice. Respir Med 1997;91:575-7 